\title{
A Body Wave Inversion of the Koyna, India, Earthquake of December 10, 1967, and Some Implications for Body Wave Focal Mechanisms
}

\author{
Charles A. Langston
}

Seismological Laboratory, California Institute of Technology, Pasadena, California 91125

\begin{abstract}
With a generalized inverse technique, WWSSN (World-Wide Standard Seismograph Network) longperiod $P$ and $S H$ wave forms are analyzed from the Koyna earthquake. The effects of local plane-layered earth structure near an imbedded point dislocation source are put in by using a modified plane-wave ray theory which includes the standard reflection and transmission coefficients plus source corrections for radiation pattern and geometrical spreading. The generalized inverse compares synthetic seismograms to the observed ones in the time domain through the use of a correlation function. By using published crustal models of the Koyna region and primarily by modelling the crustal phases $P, p P$, and $s P$, the first $25 \mathrm{~s}$ of the long-period wave forms is synthesized for 17 stations, and a focal mechanism is obtained for the. Koyna earthquake which is significantly different from previous mechanisms. The fault orientation is $67^{\circ}$ dip to the east, $-29^{\circ}$ rake plunging to the northeast, and $N 16^{\circ} \mathrm{E}$ strike, all angles being $\pm 6^{\circ}$. This is an eastward dipping, left lateral oblique slip fault which agrees favorably with the trend of fissures in the meizoseismal area. The source time duration is estimated to be $6.5 \pm 1.5 \mathrm{~s}$ from a triangular time pulse which has a rise time of $2.5 \mathrm{~s}$, a tail-off of $3.9 \mathrm{~s}$, source depth of $4.5 \pm 1.5 \mathrm{~km}$, and seismic moment of $3.2 \pm$ $1.4 \times 10^{25} \mathrm{dyn} \mathrm{cm}$. Some short-period complexity in the time function is indicated by modelling shortperiod WWSSN records but is complicated by crustal phases. The long-period $\boldsymbol{P}$ wave forms exhibit complicated behavior due to intense crustal phase interference caused by the shallow source depth and radiation pattern effects. These structure effects can explain much of the apparent multiplicity of the Koyna source. An interpretation of the Koyna dam accelerograms has yielded an $S$-P time which can be used along with the IMD (Indian Meteorological Department) epicenter and present depth determination to place the epicenter directly on the meizoseismal area.
\end{abstract}

\section{INTRODUCTION}

Application of body wave first motions in seismic source studies has long been a standard tool in seismology. In fact, much of the bridge between seismology and geologic processes has been founded upon focal mechanisms inferred mostly from body wave interpretations. Stauder [1962] gives a good review of the history and techniques involved in the firstmotion method. There are other parameters besides orientation which are of interest and have been pursued by using various methods also involving body waves. These include such quantities and concepts as source time functions, directivity, and source multiplicity. Fukao $[1970,1972]$ has studied deep-focus events by modelling the long-period $P$ and $S$ wave forms, taking into account receiver structure, $Q$, and time function effects. Abe [1974] has tried to extend the same methods of wave form synthesis to the study of shallow crustal events where the assumption of homogeneous source structure, appropriate for deep events, is still used. Bollinger [1968], using assumptions on source time functions, directivity, and earth structure, interpreted long-period $\boldsymbol{P}$ wave forms for the purpose of determining faulting direction in both deep and shallow events.

Closely related to time domain wave form methods are those which make extensive use of spectral analysis. Notably, Teng and Ben-Menahem [1965], using the methods outlined in the work by Ben-Menahem et al. [1965], analyzed $P$ and $S$ waves from a deep-focus Banda Sea event. This method is completely equivalent, of course, to modelling using time domain representations of structure, $Q$, etc. if the amplitude and phase spectra are both incorporated. In the last few years a simplified variation of Ben-Menahem et al. [1965] has become in conjunction with Brune's [1970] ideas on the behav-

Copyright $\odot 1976$ by the American Geophysical Union. ior of the seismic source time function. Hanks and Wyss [1972], making simplifying assumptions about earth structure, have outlined a spectral technique which compares an observed body wave spectrum to that of a Brune time function. Making assumptions about the relations between frequency content and source dimensions, they obtain the stress drop and moment for observed earthquakes.

In addition to these involved analysis techniques there are many studies of source mechanisms which include interpretations of the arrival time of observed phases. The 'multiplet' technique [Oike, 1971], for instance, seems to be a simple, yet powerful method for determining source propagation effects in deep earthquakes. Very closely related are the ideas first put forth by Wyss and Brune [1967] on multiple sources. Interpreting various arrivals on short-period observations from the Alaskan earthquake of March 28, 1964, as multiple sources, they established a seismological precedent in source studies. Numerous authors studying other shallow events have appealed to such source complications in the same way, a few being $W u$ [1968], Niazi [1969], and Gupta et al. [1971].

Most of the techniques discussed above suffer some serious form of limitation by themselves or when a shallow crustal source is involved. First motions have an intrinsic difficulty in that the very first motion of an earthquake may have nothing to do with the rest of the earthquake. The spectral techniques involve a transformation from the time domain into the frequency domain, so that the details and characteristics of the observed record become obscured and harder to interpret. The effect of local earth structure around the source is the largest unknown factor in all of the shallow source interpretations mentioned. It is nearly always neglected but, as will be shown in this paper, is the most important and obvious feature of a shallow seismic source.

By using the long- and short-period wave forms from a shallow earthquake, various hypotheses about the source and 


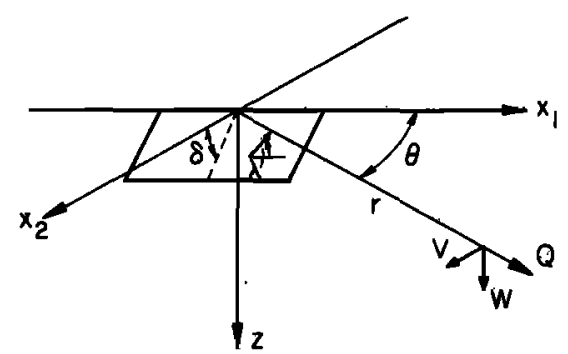

Fig. 1. Dislocation geometry and conventions.

local earth structure will be tested by modelling them in the time domain. The objectives will be (1) to take a shallow earthquake which has been studied extensively and is of great interest but has yielded inconsistent and problematical interpretations to test the dislocation model and to determine the parameter's of the earthquake, (2) to determine how much of the seismogram is controlled by source and how much by earth structure, and (3) to reach conclusions concerning the reasons for success or failure of the previous source interpretations and the limitations of the present methods.

The earthquake studied here will be the Koyna, India, earthquake of December $10,1967(M=6.4)$, which seemingly occurred in consequence of a nearby hydroelectric project. The goal will be to model the long- and short-petiod wave forms for this event by using a modified plane-wave ray theory discussed by Langston and Helmberger [1975] in conjunction with a generalized inverse to determine the source depth, time function, fault orientation, and, if any, source complications.

\section{TheORY}

The details of the Cagnaird derivation of an arbitrarily oriented point shear dislocation in a layered medium are given in the work by Langston and Helmberger [1975] and Helmberger [1974] and will only be reviewed here.

Figure 1 displays the coordinate system and fault geometry used in this scheme.

Plane-layered earth structure is modelled by summing the ray contributions of each reflection and transmission considered. The far-field dislocation time function, $S(t)$, is normalized to have unit area or

$$
\int_{-\infty}^{+\infty} S(t) d t=1
$$

Instrument responses, $I(t)$, in this paper will be either the longperiod WWSSN (World-Wide Standard Seismograph Network) response calculated by using the equations of Hagiwara [1958] used in the long-period synthetic calculations or the short-period WWSSN response (L. Burdick and G. Mellman, personal communication, 1975) used in the short-period synthetic calculations. The $Q$ operator, $Q(t)$, is that derived by Futterman [1962] and modified by Carpenter [1966] to incorporate an average value of $T / Q$, where $T$ is the travel time and $Q$ is the seismic quality factor. The values 1.0 and 4.0 for $T / Q$ will be assumed for $P$ and $S$ waves, respectively.

The philosophy behind the modelling procedure is as follows. Independent determinations of layer parameters from travel time studies and refraction profiles are used for earth structure around the source. Assuming a simple starting model for the source based on first-order epicentral locations and interpretations of the data seismograms, synthetic seismograms are computed and compared with the originals. Generally, this entails the use of only one point source in the layered medium at first. The number of rays computed for the medium depends on how much of the record is considered. For example, if $30 \mathrm{~s}$ of record is to be modelled, all rays with arrival

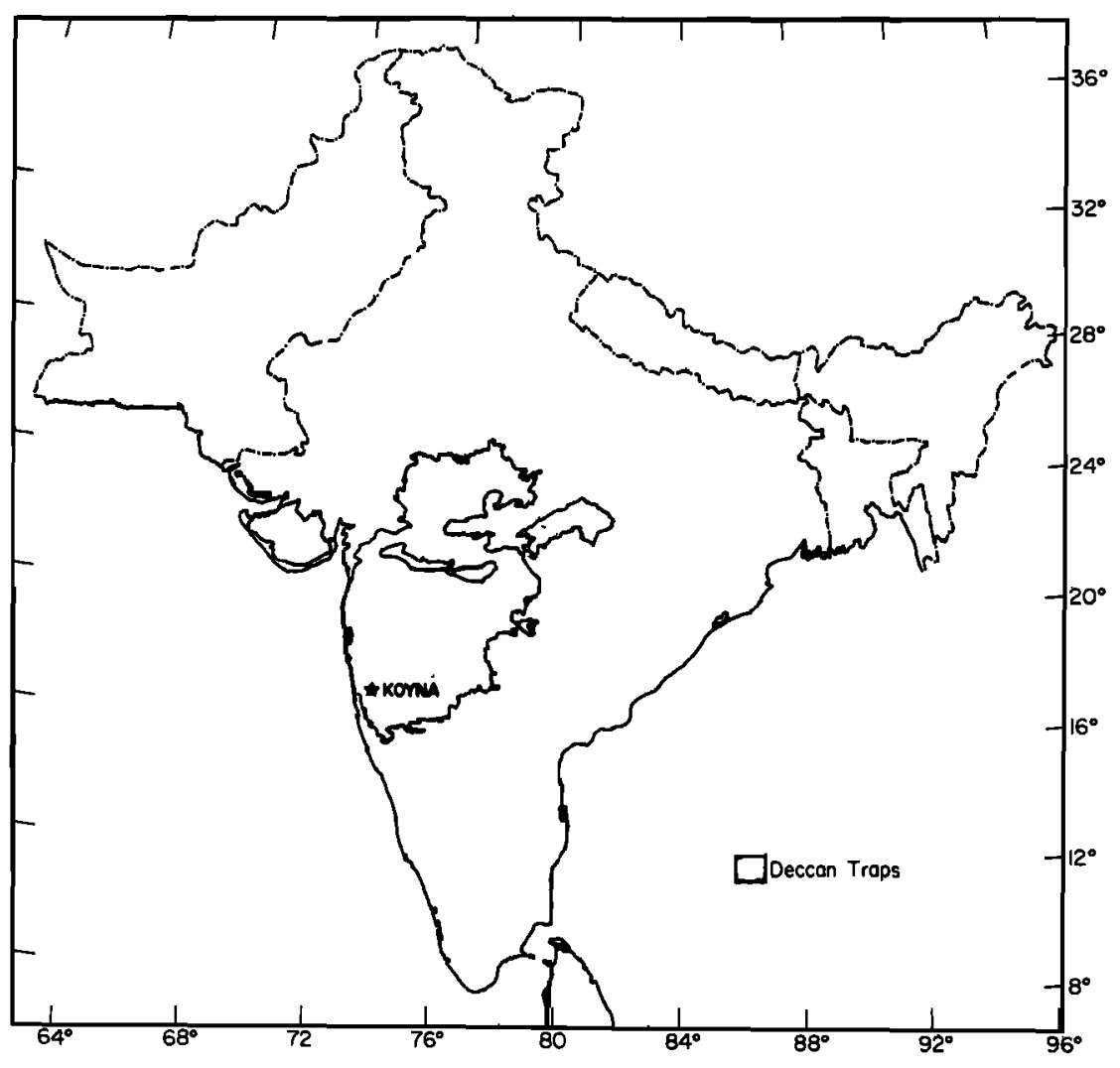

Fig. 2. Index map of the Indian region showing the location of the Koyna area. 
times within this period are tested. Often it turns out that many of the rays contribute virtually nothing to the response, so these are discarded to simplify calculations. Several forward problem runs are made to improve the fits and to determine which effects, source or structure, are important in explaining various features of the seismogram. If the one-source model seems sufficient, an inversion run is made. It must be emphasized that the model is initially kept as simple as possible. If the data inversion indicates that more sources or more structure is needed to explain the seismogram, then, and only then, are more complications put in and only with the highest justification. It is precisely for these reasons that the point dislocation model is so well suited to this type of problem.

\section{The Koyna Earthquake}

On December 10, 1967, a sizable earthquake $(M=6.4)$ occurred near the Koyna Dam and Shivajisagar Lake area of western central India (Figure 2). This event is significant, since it occurred in what was previously considered an aseismic part of the Indian shield. It is also unusual in that it almost certainly seems to be intimately related to the impoundment of the nearby reservoir. Numerous authors [Narain and Gupta, 1968; Guha et al., 1970; Aki, 1972] have described the details and significance of the events leading up to and including the main shock of the Koyna earthquake series, so these will not be discussed here.

Geologically, the area lies near the western margin of the Deccan trap basalts of Late Cretaceous to Paleocene age (Figure 2). These basalts are believed to be underlain by granitic basement [Narain, 1973]. They are about 6-7 km thick near the coast, thinning to about $1 \mathrm{~km}$ in the Koyna area and thickening to about $3 \mathrm{~km}$ eastward [Guha et al. 1976].

The history of study of this earthquake is as interesting and diverse as the circumstances surrounding it. For example, Figure $3 a$ shows the collection of fault plane solutions done by various authors. As can be seen, there seems to be some ambiguity concerning the orientation of the Koyna fault. Gupta et al. [1969, 1971] claim the Koyna source to be an extremely complex multiple shock with rupture propagating from south to north on a vertically dipping fault plane. This is based on interpretations made on short-period $\boldsymbol{P}$ phases in the tradition of Wyss and Brune [1967]. Because the earthquake was so widely felt but also caused high intensities locally, many workers support a very deep source which propagated to the surface. In particular, Gorbunova et al. [1970], from the study of $\boldsymbol{P}$ arrival times, postulate that the earthquake initiated at a depth of $80 \mathrm{~km}$ and propagated upwards along a steeply dipping fault plane about $25 \mathrm{~km}$ wide with vertical and horizontal rupture velocities of $8 \mathrm{~km} / \mathrm{s}$ and $3 \mathrm{~km} / \mathrm{s}$, respectively. Tsai and $A k i$ [1971] studied surface waves from the event and reached a similar conclusion, obtaining a depth of about 55 $\mathrm{km}$ to explain the observed radiation pattern. Guha et al. [1970], however, attribute the large size of the felt area not to deep hypocentral depths but to the efficient propagation of $\mathbf{L g}$ in the Indian shield due to a shallow source in the continental wave guide.

Intertwined with these interpretations are the discrepancies observed in epicentral locations. By partitioning the $\boldsymbol{P}$ wave

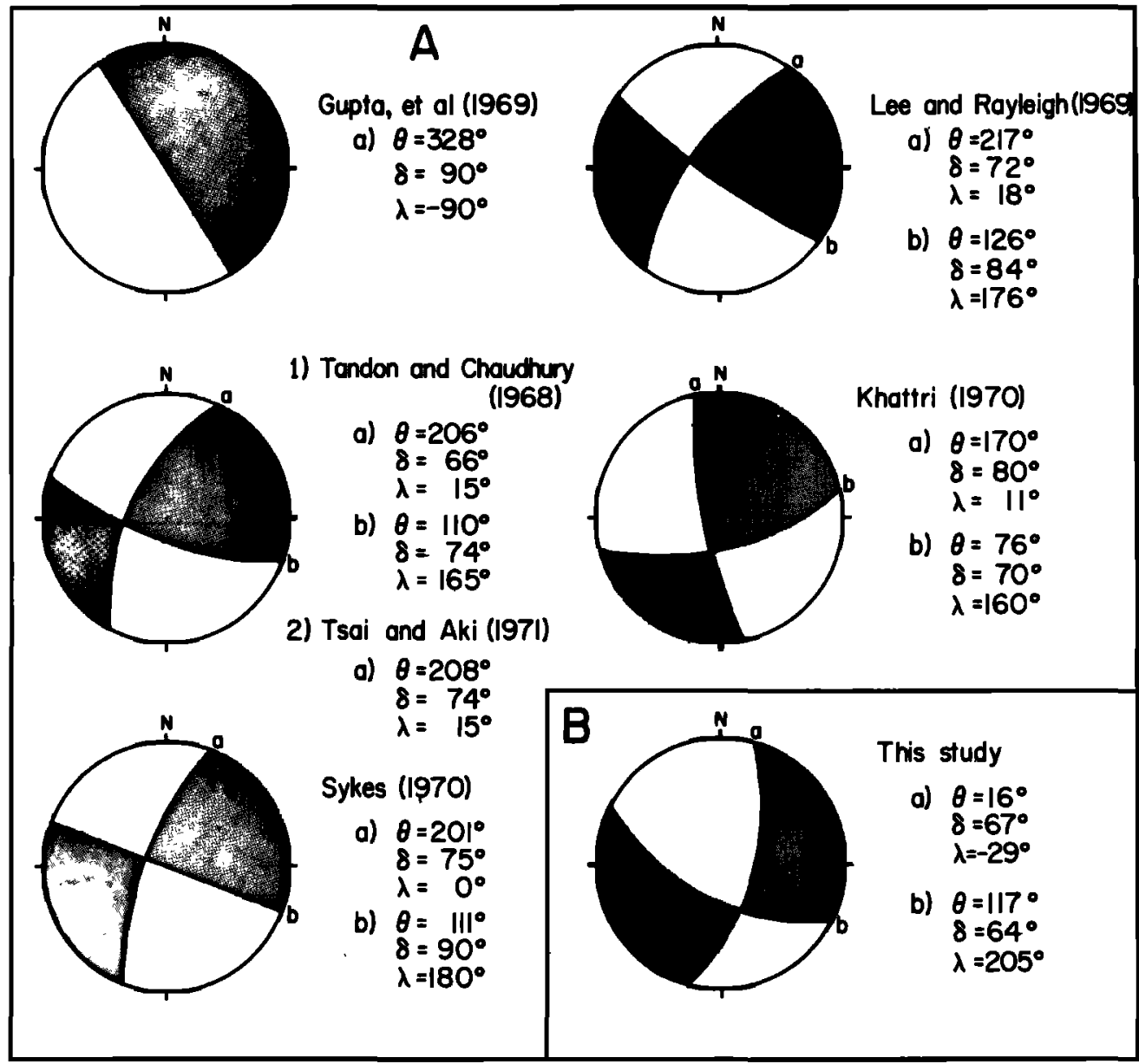

Fig. 3. Focal mechanisms done by various authors for the Koyna earthquake. 
arrival time data set into several categories based on distance, several authors have noted trends in the computed epicenters obtained from each set. This type of calculation was the basis for the studies made by Gorbunova et al. [1970] and Gupta et al. [1971]. Thus even though there is good isoseismal evidence, the hypocentral location is very poorly known.

\section{Data Processing}

Copies of all the available WWSSN long- and short-period recordings for the Koyna event were procured. Records for long-period $\boldsymbol{P}$ and $\boldsymbol{S H}$ waves were chosen for wave form inversion on several criteria. Wave forms were used which had a signal to noise ratio of 5 or better and a minimum amplitude of approximately $1 \mathrm{~cm}$ on the enlarged record, so that line thickness errors would be small. $\mathrm{SH}$ waves had to be naturally rotated with the $S V$ component comparable or smaller than $S H$ to eliminate $P L$ wave problems. In addition, stations were between $30^{\circ}$ and about $85^{\circ}$ in order to avoid upper mantle structure effects. Thirteen $P$ waves and six $S H$ waves were finally chosen (Table 1). Azimuthal coverage is good for this data set except in southeasternmost azimuths.

Each seismogram was digitized 4 times (the trace line top and bottom twice) at an irregular interval of two to three points per trace second and interpolated at four points per trace second. The four traces were then averaged to obtain the final digital form. A deskewing operation was also applied to the wave forms to eliminate the image skew inherent in the seismograph recording system [Mitchell and Landisman, 1969]. This had negligible effect on most records but was important for some of the high-amplitude $S H$ waves.

TABLE 1. WWSSN Stations for Long-Period $P$ and $S H$

\begin{tabular}{|c|c|c|c|c|c|}
\hline Station & $\Delta, \operatorname{deg}$ & $\begin{array}{l}\text { Azimuth, } \\
\text { deg }\end{array}$ & $\begin{array}{c}\text { Back } \\
\text { Azimuth, } \\
\text { deg }\end{array}$ & $\boldsymbol{P}$ & $S H$ \\
\hline $\begin{array}{l}\text { AAE } \\
\text { ADE } \\
\text { ANP } \\
\text { AQU } \\
\text { ATU } \\
\text { BAG } \\
\text { COP } \\
\text { CTA } \\
\text { DAV } \\
\text { ESK } \\
\text { HKC } \\
\text { HNR } \\
\text { IST } \\
\text { JER } \\
\text { KEV } \\
\text { KON } \\
\text { MAT } \\
\text { MUN } \\
\text { NAI } \\
\text { NOR } \\
\text { NUR } \\
\text { PMG } \\
\text { PRE } \\
\text { SDB } \\
\text { SHK } \\
\text { STU } \\
\text { TAB } \\
\text { TOL } \\
\text { TRI } \\
\text { UME } \\
\text { VAL } \\
\text { WIN }\end{array}$ & $\begin{array}{l}35.0 \\
80.6 \\
45.0 \\
56.7 \\
48.2 \\
44.7 \\
59.7 \\
80.3 \\
51.5 \\
68.5 \\
38.3 \\
89.2 \\
45.0 \\
37.7 \\
59.6 \\
62.1 \\
59.5 \\
63.8 \\
40.8 \\
73.0 \\
55.4 \\
77.2 \\
61.6 \\
67.5 \\
55.0 \\
60.3 \\
31.7 \\
69.8 \\
56.9 \\
58.8 \\
72.9 \\
68.2\end{array}$ & $\begin{array}{r}260.8 \\
131.0 \\
71.6 \\
309.6 \\
305.6 \\
84.0 \\
324.9 \\
114.6 \\
94.8 \\
323.2 \\
75.9 \\
100.1 \\
311.1 \\
299.7 \\
342.9 \\
328.9 \\
57.5 \\
140.2 \\
246.8 \\
351.2 \\
333.0 \\
104.2 \\
227.0 \\
245.2 \\
59.8 \\
316.6 \\
316.2 \\
306.7 \\
313.5 \\
335.4 \\
319.9 \\
236.3\end{array}$ & $\begin{array}{r}72.64 \\
298.7 \\
269.8 \\
96.7 \\
100.9 \\
278.3 \\
104.0 \\
292.5 \\
286.5 \\
90.5 \\
270.1 \\
287.6 \\
108.0 \\
103.1 \\
126.3 \\
103.6 \\
269.7 \\
314.0 \\
61.4 \\
87.0 \\
118.8 \\
290.2 \\
50.7 \\
63.8 \\
267.7 \\
97.4 \\
123.1 \\
83.9 \\
99.1 \\
116.2 \\
83.7 \\
59.3\end{array}$ & $\begin{array}{l}a \\
b \\
b \\
a \\
b \\
b \\
b \\
a \\
b \\
b \\
a \\
b \\
a \\
a \\
b \\
a \\
a \\
b \\
a \\
b \\
b \\
a \\
a \\
a \\
b \\
b \\
a \\
b \\
b \\
b \\
b \\
b\end{array}$ & $\begin{array}{l}a \\
a \\
b \\
b \\
a\end{array}$ \\
\hline
\end{tabular}

$a$, used in the inversion; $b$, used but not in the formal inversion.
For interpretive purposes, $21 S$ wave rotations into the ray direction were performed with varying degrees of success. A successful rotation was one for which the ' $P$ ' amplitude was a factor of 2 or 3 lower than any $S$ wave. Out of these, only about 10 were considered good.

The final $\boldsymbol{P}$ and $\boldsymbol{S H}$ wave forms were then passed through a deconvolution operator which removed the response of the WWSSN 15-100 instrument. The process was carried out in the frequency domain by using the fast Fourier transform and is shown by the following equation:

$$
F(\omega)=\frac{S(\omega) a(\omega)}{I(\omega)}
$$

where $S(\omega)$ is the Fourier transform (FT) of the digitized trace, $I(\omega)$ is the FT of the instrument response, $a(\omega)$ is a light bandpass filter to remove high-frequency noise, and $F(\omega)$ is the FT of the deconvolved trace. The $a(\omega)$ used was simply the $Q$ operator at a low value of $T / Q=0.25$. In the time domain this is essentially a spike approximately three quarters of a second in duration: The reconvolution of the instrument with the deconvolved trace always reproduces the original record with virtually no change. Since the deconvolutions are for interpretation purposes only, this filter proved quite adequate. Figure 4 shows the $P$ and $S H$ data used with their corresponding deconvolutions. Note the African stations AAE and NAI. Gupta et al. [1969] discarded these stations on the basis of their anomalously high positive $\boldsymbol{P}$ residuals, claiming that the $\boldsymbol{P}$ first motions were missed. However, these stations proved to be of the highest quality on the basis of noise and amplitude, and both short- and long-period first motions are clear. Long et al. [1973] report that the average $P$ residual beneath these stations is about $+2.5 \mathrm{~s}$ and attributable to low velocities in the East African upper mantle.

\section{Data Inversion Procedure}

Since standard techniques for producing a focal mechanism for the Koyna earthquake have proved contradictory, making a starting model proved to be a complicated process. By using the deconvolutions of Figure 4 in conjunction with the figures in the work by Langston and Helmberger [1975], trial hypotheses were made for the observed phases. For example, at station PMG (Figure 4) the first downswing can be considered to be the direct $\boldsymbol{P}$ wave, and the next prominent upswing, the phase $p P$ or $s P$. Once a trial model is deduced, it is further tested by computing synthetic seismograms and comparing them with the originals.

Table 2 contains the various crustal structures considered in this study. Crust 1 obtained from Narain [1973] was used in the starting model calculations and inversions. This model is based on earthquake travel times and surface wave studies, so the nature of the boundaries is essentially unknown. This point will be investigated later in the paper.

The starting model determined from these trial and error techniques is a simple one-point source model with the parameters displayed in Table 3 . The time function was chosen to be a simple triangular pulse characterized by a rise time, $\delta t_{1}$, and falloff, $\delta t_{2}$. This was determined mostly by the general shape of the observed phases. A treatment of the errors involved in these assumptions will follow the results.

In the calculations of the starting model and in the inversion the receiver structure is taken to be simply a homogeneous half space. For $P$ waves impinging under the receiver crust the most important ray in the receiver response is the free surface to Moho to free surface reflection. Its relative travel time, to 


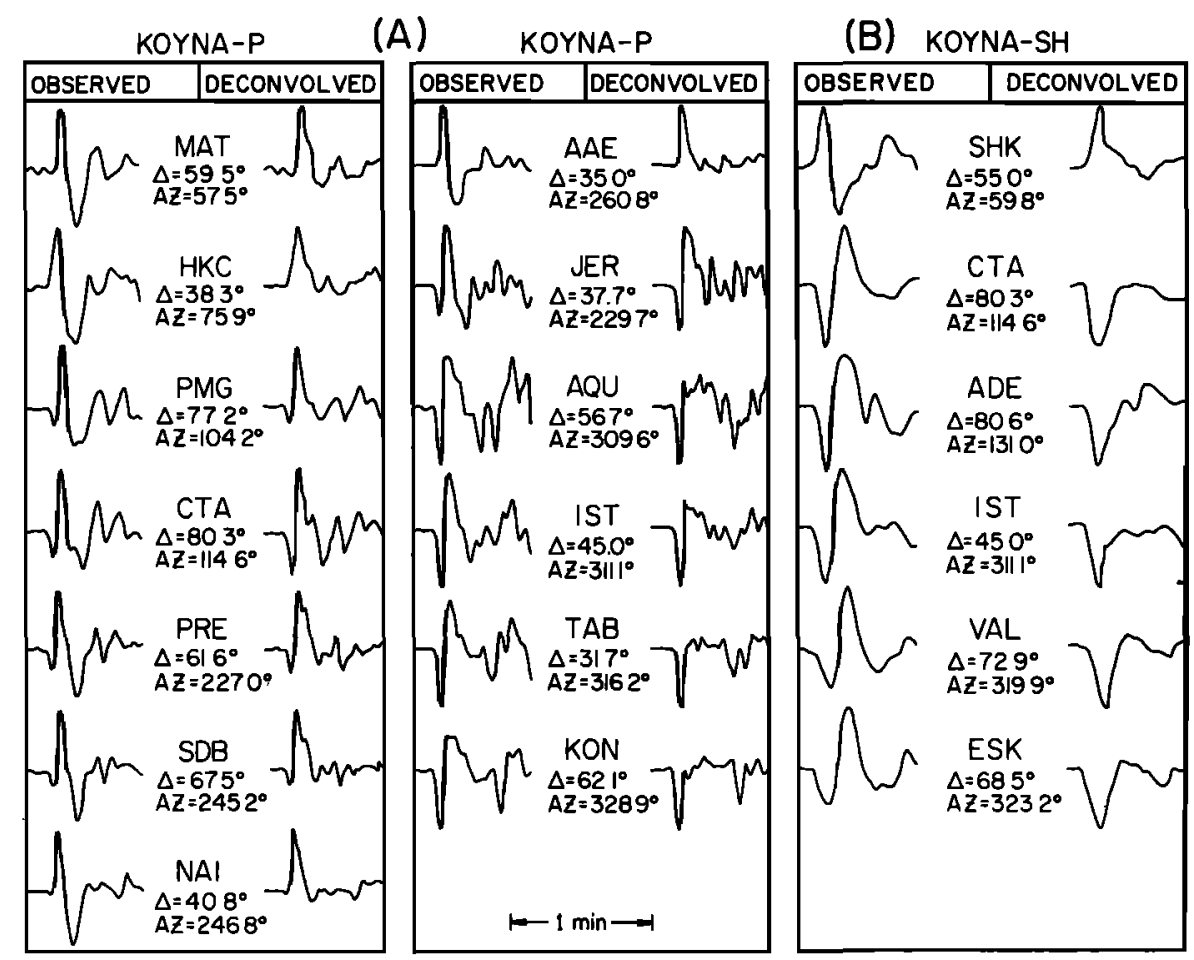

Fig. 4. (a) Long-period WWSSN $P$ wave forms used in this study with their respective instrument deconvolutions. (b) $S H$ wave forms.

the direct arrival, is about $10 \mathrm{~s}$ for typical crustal models, and its amplitude about $10 \%$ of the direct ray. For $\boldsymbol{S H}$ the first 'bounce' is slightly larger but occurs farther back in the record. At the beginning of the study an attempt was made to estimate receiver crustal structures but was effectively thwarted by the lack of good crustal models beneath the WWSSN stations. Because these arrivals are small, they are ignored and can be considered a source of noise in the inversion.

\section{INVERSION RESULTS}

The appendix contains a detailed description of the inversion procedure incorporated in this study. The actual inversion was performed in a stepwise manner. Since it was difficult to find a starting model which would simultaneously fit the $S H$ and $P$ data together, only $P$ waves were used first in hopes of bringing the model closer to compatibility. The average fit for the $P$ waves started at 0.9455 , the value of the correlation function, and after two interactions increased to about 0.9600 . The $S H$ waves were then added, and it was found that the new starting model was sufficient for the program to continue. After about three more iterations the step

TABLE 2. Crustal Models

\begin{tabular}{ccccc}
\hline Model & $\alpha, \mathrm{km} / \mathrm{s}$ & $\beta, \mathrm{km} / \mathrm{s}$ & $\rho, \mathrm{g} / \mathrm{cm}^{\mathrm{g}}$ & Thickness, $\mathrm{km}$ \\
\hline \multirow{2}{*}{1} & 5.7 & 3.5 & 2.6 & 20.0 \\
& 6.5 & 4.0 & 2.8 & 20.0 \\
2 & 8.2 & 4.7 & 3.2 & \\
& 5.7 & 3.5 & 2.6 & 15.0 \\
& 6.3 & 3.6 & 2.7 & 5.0 \\
& 6.8 & 3.9 & 2.8 & 15.0 \\
& 7.4 & 4.3 & 3.0 & 5.0 \\
3 & 8.2 & 4.7 & 3.2 & 20.0 \\
& 6.0 & 3.5 & 2.6 & 20.0 \\
& 6.8 & 3.9 & 2.8 & \\
\hline
\end{tabular}

size became negligible, and the inversion was terminated. The final model reached an average fit of 0.9731 . Only the first 10-12 s of each record was used because of crustal structure uncertainties which will be discussed in the error analysis. However, nearly all of the important information is contained within this time period. The phases $P, p P, s P, S$, and $s S$ all arrive within this time because of the shallow source depth.

Table 3 gives the results of the inversion. Figure $3 b$ gives the focal plot representation. As can be seen, not too much changed except for the depth and strike. Even so, this was significant for the quality of fit, significant in the respect of just fitting the observed first motions and general wave shape behavior. Figure 5 shows the data and synthetics for the final model for the time length used. Figure 6 shows the first $60 \mathrm{~s}$ of the observed $P$ waves and the full synthetic calculation using 24 rays in crust 1 (Table 3 ), with arrival times up to $26 \mathrm{~s}$ after the direct $\boldsymbol{P}$ arrivals. The overall fit is striking, although some details are lacking in the synthetics. Generally, the model predicts all stations to have dilatational direct $P$ arrivals except for HKC. The only possible discrepancy may be MAT, but the long- and short-period first-motion signal is in the noise, so it is certainly acceptable. The synthetic direct $P$ wave for AAE is too. large, but the first motion on the long- and short-period records is clearly dilatational.

TABLE 3. Source Models

\begin{tabular}{lrrr}
\hline & & \multicolumn{2}{c}{ Final } \\
\cline { 3 - 4 } & Starting & Crust 1 & Crust 3 \\
\hline$\delta$ & $70.0^{\circ}$ & 67.0 & 72.0 \\
$\lambda$ & $-30.0^{\circ}$ & -29.0 & -26.0 \\
$\theta$ & $30.0^{\circ}$ & 16.0 & 20.0 \\
$H S, \mathrm{~km}$ & 10.0 & 4.4 & 4.6 \\
$\delta t_{1}, \mathrm{~s}$ & 2.5 & 2.5 & 2.5 \\
$\delta t_{2}, \mathrm{~s}$ & 2.5 & 3.9 & 4.0 \\
\hline
\end{tabular}




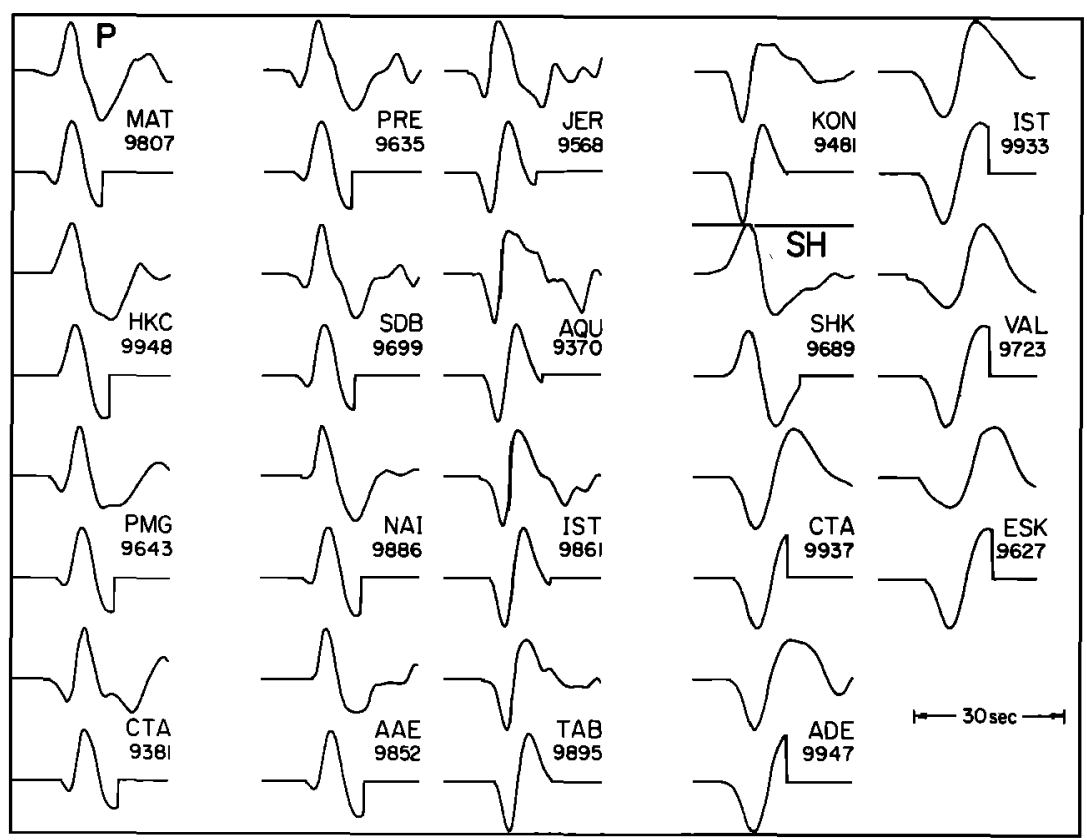

Fig. 5. Final fit for the combined inversion of the $P$ and $S H$ wave data showing the quality of fit at each station and amount of record used. At each station the observed is on top, and the calculated is directly below.

On all stations in the azimuth range between $57^{\circ}$ and $300^{\circ}$ the prominent upswing after the $P$ wave consists of the surface reflections $p P$ or $s P$. It is interesting to note that this upswing is not the same phase at all stations. In southeastern azimuths it is mostly $p P$ and in southwestern azimuths, $s P$. The group of stations AQU, IST, TAB, and KON demonstrates a remarkable interference phenomenon which is predicted by the model. Note the deconvolutions of these stations in Figure 6. The $\boldsymbol{P}$ wave seems to behave as one sharp dilatational pulse with some smaller oscillations occurring behind it. The model, however, predicts a positive $\boldsymbol{s} \boldsymbol{P}$ phase which is comparable in amplitude to the negative direct $\boldsymbol{P}$. Because of the extremely shallow source depth and length of the time function, $s P$ is almost totally annihilated by the direct $P$. It is precisely this interference which controls the depth determination.

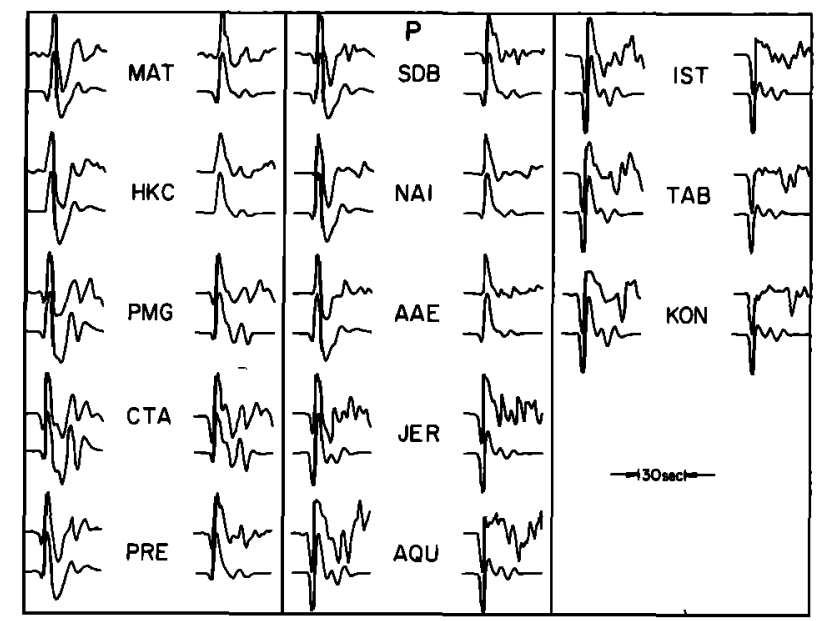

Fig. 6. Comparison of the observed and calculated $P$ waves for approximately the first $30 \mathrm{~s}$ of record. At each station the observed is on top with the synthetic directly below. To the left of the station, letters are the observed and calculated with the instrument response and to the right they are the observed and calculated without the instrument response.
In addition to the major crustal phases caused by the free surface there are significant arrivals in the $\boldsymbol{P}$ wave which are caused by internal boundaries such as the Moho and the Conrad discontinuities. These later arrivals usually correspond to rays which suffer not more than one $S$ to $P$ conversion and are mostly in the $P$ mode in the source crust. The major contributors are those which bounce off the Moho, back to the free surface, and then down again. As might be expected, these arrivals are not completely coherent over all stations, although there are many good correlations between data and synthetic. These rays will be sensitive to the precise nature of the boundaries and total travel time through the crust. It is speculated that the major reason that these arrivals are not as well behaved as predicted is because of the real earth's deviation from plane isotropic layers. However, the fact that these phases even exist where they do certainly places ambiguity on just what can be attributed to source effects.

Of all the stations used, PMG and CTA undergo the most extreme crustal distortions of the source. Because of strong upgoing and downgoing $S V$ radiation relative to the $P$ radiation at these distances and azimuths, fairly large $S$ to $P$ conversions occur at the Conrad, Moho, and free surface of crust 1 (Table 2). Since sharp boundaries like these probably do not occur in real crusts, a model calculation was done to see what effect changing the nature of these boundaries had on the fits. Figure 7 shows the result of such a calculation. The Australian $\boldsymbol{P}$ wave station ADE is included here. It was not included in the formal inversion because of very low amplitude even though there is very little noise. The digitization of this station is somewhat poor because of record line thickness problems but is sufficient for semiquantitative comparisons of relative amplitudes and arrivals. The synthetics made from crust 1 in Figure 7 show two deficiencies. The calculated direct $\boldsymbol{P}$ wave is too small, in general, and the later arrivals of the $\boldsymbol{S}-\boldsymbol{P}$ phases are too large. The predicted wave form for ADE is pathological. However, when small transition layers are put into the crustal structure, (crust 2, Table 2), the synthetics improve their relative amplitude behavior for both the direct $\boldsymbol{P}$ 

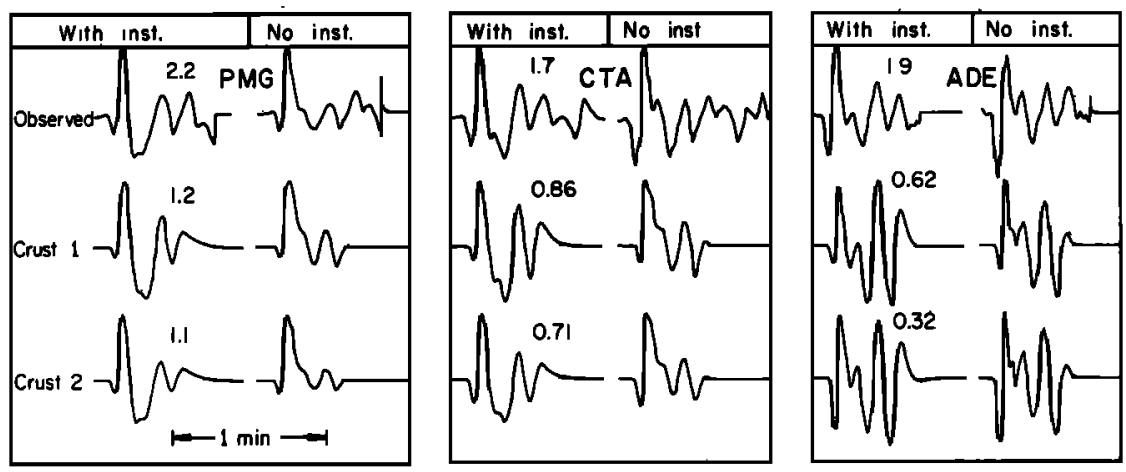

Fig. 7. Model calculation (for two crustal structures) involving the three stations which show the greatest structural interference.

and the later arrivals. The later arrivals at ADE are still too big, but the direction of improvement is obvious.

Other crustal effects can also enter in. For example, the effect of a near-surface layer can significantly affect the reflection coefficients at the free surface. A layer representing the Deccan traps was not included principally because so little is known of the Koyna crustal structure. Velocity measurements indicate fairly high compressional velocities of the order of 5-6 $\mathrm{km} / \mathrm{s}$ [Kailasam et al., 1969]. This can be used as justification of the crustal model. However, these arguments point out what seems to be the major difficulty with this method: unless the crustal structure is precisely known, exacting source interpretations are very hard to make.

Figure 8 shows the observations and synthetics for the $S H$ waves. They behave in a much less complicated fashion than the $P$ waves. Primarily, they contain only the phases $S$ and $s S$ with other crustal multiples playing a minor role. The second major pulse at $A D E$ is probably $S c S$. The relative $J-B$ arrival time is correct for this range. The stations VAL and ESK show some unpredicted effects. Although the pulse widths as shown by the deconvolutions are comparable, their rise times certainly are not. The data, especially at ESK, have an exceptional slow rise. Several explanations are possible, of course, among them being source directivity and $Q$ effects. Because the data set is so limited, however, no attempt will be made to explain these particular problems.

A comparison of synthetic with data was also done for the high noise and rotated stations for both $P$ and $S$, and in virtually all cases the qualitative fit was good. Table 1 contains these stations. Note, for example, the well-defined $S H$ node predicted by the model at an azimuth of about $340^{\circ}$. Figure 9

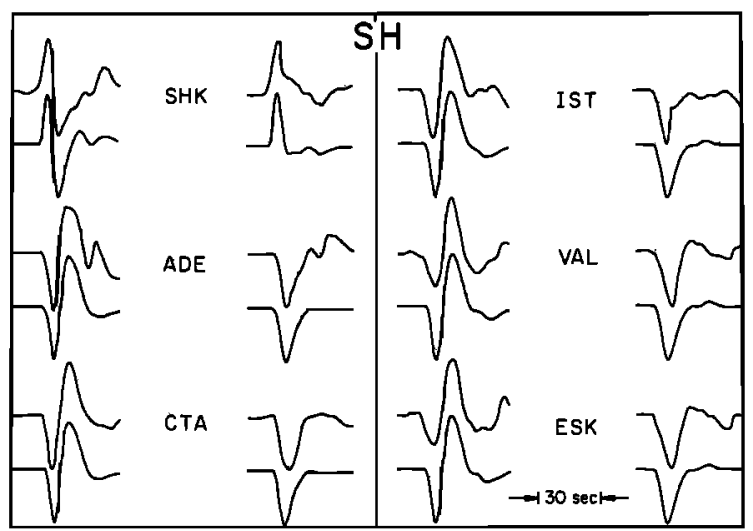

Fig. 8. Comparison of the observed and calculated $S H$ wave forms. The scheme is the same as in Figure 7. shows the qualitative fit of rotated $S H$ waves near this azimuth with the predicted model.

In addition to the parameters of Table 3 the absolute scaling of the synthetics to the data yields a moment determination. Table 4 contains the results for the stations used. The $P$ waves exhibit more scatter than the $S H$ waves possibly because they are controlled by the local crustal structure to a larger extent. The average moment for $P$ and $S H$ combined is $3.2 \pm 1.4 \times$ $10^{26}$ dyn $\mathrm{cm}$.

To determine the relative importance of any particular station to the inversion, a useful technique is to examine the eigenvectors of the observations through the use of the data 'resolution' matrix [Wiggins, 1972], defined by

$$
\mathbf{R} \mathbf{u}=\mathbf{U U}^{\mathbf{T}}
$$

$(R u)_{u}$ contains the least squares solution for the importance of the $i$ th datum. The closer $(R u)_{u}$ is to unity, the more importarit the $i$ th datum was in determining the solution of the inverse problem as opposed to values of $(R u)_{\|}$which are closer to zero. Figure 10 is a polar diagram of the stations used in the inversion plotted as a function of their azimuth and relative importance defined by (3). Total importance, or in this case $\operatorname{Tr} \mathrm{Ru}=6$, has been normalized to unit amplitude, and the relative importance of éach station taken as a percentage. The distribution observed in Figure 10 is a product of several factors. Assuming that statistical noise is equal for each station, the higher values of importance partially means that the

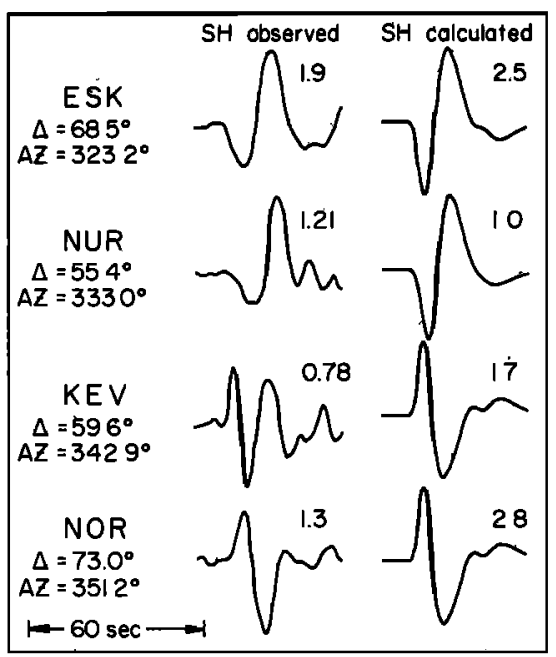

Fig. 9. Qualitative fit for rotated $S H$ waves near an $S H$ node. The right side contains the predicted wave forms, and the left the observed. 
TABLE 4. Moment Calculation

Station $\because \begin{gathered}\text { Moment, } \\ \times 10^{08} \text { dyn cm }\end{gathered}$

$\begin{array}{lr} & \text { Values for } P \\ \text { AAE } & 0.40 \\ \text { AQU } & 0.10 \\ \text { CTA } & 0.60 \\ \text { HKC } & 0.21 \\ \text { IST } & 0.14 \\ \text { JER } & 0.24 \\ \text { KON } & 0.14 \\ \text { MAT } & 0.25 \\ \text { NAI } & 0.30 \\ \text { PMG } & 0.60 \\ \text { PRE } & 0.39 \\ \text { SDB } & 0.30 \\ \text { TAB } & 0.16 \\ \text { average } & 0.29 \\ \sigma & 0.16 \\ & \text { Values for } \\ \text { ADE } & 0.50 \\ \text { CTA } & 0.42 \\ \text { ESK } & 0.29 \\ \text { IST } & 0.31 \\ \text { SHK } & 0.30 \\ \text { VAL } & 0.37 \\ \text { average } & 0.37 \\ \sigma & 0.08\end{array}$

station produced large partial derivatives because parameters were changing quickly in the model space. Thus these stations were very important in the real sense of producing a better model. However, since a true parameterization of the seismic event which can explain every datum perfectly is most likely impossible, a high importance can also reflect model deficiencies. If Figures 5 and 10 are compared, it seems that the latter reason is the predominant one. Good fits have low importances, and bad fits have high importances, in general, the implication being that the model is deficient in its assumptions on this level.

Since this is an overdetermined problem, standard techniques can be used to study the errors induced by the observations onto the model space.

Examining the 'error' matrix of the system [for example, see Minster et al., 1974; Alewine, 1974] and finding the 95\% confidence ellipses for pairs of parameters using a standard error which implies that the best fit cannot exceed 0.99 (G. Mellman

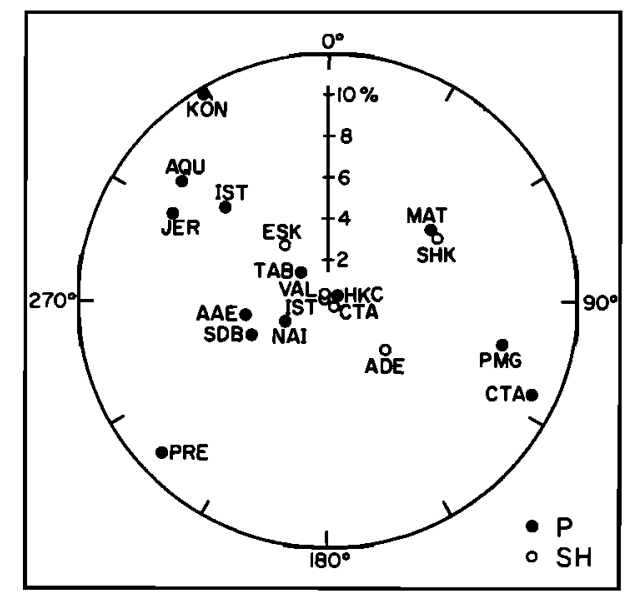

Fig. 10. Data importance plotted as a function of azimuth on a polar diagram. and L. Burdick, personal communication, 1975) give the expected result of very small errors. On the assumption that the maximum excursions of the two-dimensional error ellipses are some indication of error, the depth is precise to $200 \mathrm{~m}$; dip, $1^{\circ}$; strike and rake, $2^{\circ} ; \delta_{t_{1}}, 0.3 \mathrm{~s}$; and $\delta_{t_{2}}, 0.4 \mathrm{~s}$. Needless to say, these errors are only apparent and are not a true indication of the deficiency of the model. The two-dimensional error ellipsoids represent cuts through the six-dimensional surface and may not be an indication of maximum attainable excursions. If the principal axes of the error ellipsoid are examined, however, the same story is repeated with the exception of $\delta t_{2}$, which attains a maximum excursion of $0.8 \mathrm{~s}$.

To get some idea of the real deficiencies in the model, another inversion was run with a different crustal model, crust 3 of Table 2. The last entry of Table 3 shows the results. Changing the $P$ velocity of the source layer primarily changed the takeoff angles and is reflected in the changes in fault orientation. This model gave virtually the same overall fit. In detail, however, some stations, such as PMG and CTA, were substantially degraded (e.g., first motions were reversed), although others were improved. This model cannot be ruled out even though it is not preferred. It will be used, however, as an estimate for the variation in orientation angles, which, taken in conjunction with the error ellipses, give extremal values for the errors in $\theta, \delta$, and $\lambda$ as about $\pm 6^{\circ}$.

The comparison of short-period observations with longperiod observations at the same station proved interesting for estimating the uncertainties in the source time function. Figure 11 shows the representative long-period/short-period comparisons for the $P$ wave data set. One of the most striking effects observed is the discrepancy in apparent travel times between the long- and short-period records. Consistently, at those stations which have low noise characteristics, the shortperiod first arrival is about $1 \mathrm{~s}$ before the apparent long-period arrival. This is certainly compelling evidence for a small foreshock before the main event. Gupta et al. [1971] make a case for such an effect from interpretations of short-period teleseismic and local observations. They interpret a small arrival before the main burst of energy as the foreshock. In detail,

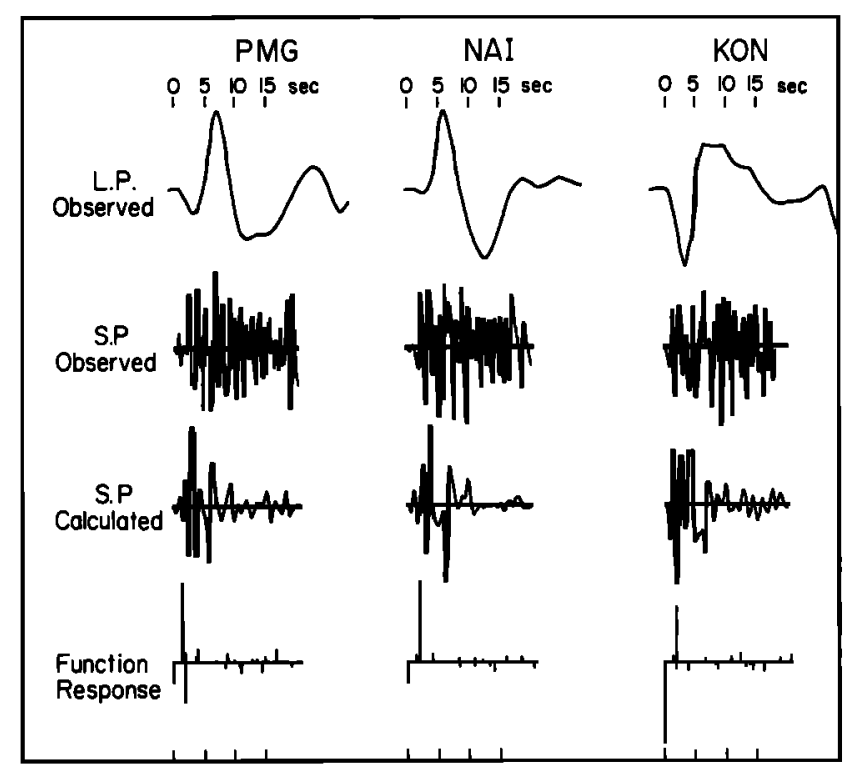

Fig. 11. Comparison of representative long-period and short-period records at three stations. Shown below are synthetic short-period records and the source crustal delta function response used. Ėach record is aligned with respect to zero time. 
however, the story is much more complicated. Assuming that this foreshock occurted in the same general area and is of similar orientation as the main shock, it will be subject to the same earth response as the main shock. That is, the amplitude and travel time of the major phases will be subject to the source orientation and depth. The bottom half of Figure 11 illustrates the result of a modelling experiment which attempted to reproduce the major effects of the short-period records. The time function used was that of Figure 12, which contains a small triangular precursor and minor modifications of the simple triangular pulse, which were needed to enhance the high-frequency nature of the short-period records. The convolution of the short-period instrument, convolved with the $Q$ filter, with this pulse is a complicated looking time series due to the sensitivity of the short-period instrument to slope changes. Convolving this with the earth response, as shown in the bottom half of Figure 11, produces synthetics which resemble the observations. At PMG and NAI there is a smallamplitude arrival about $2 \mathrm{~s}$ before a larger arrival. At KON the $P$ wave is more impulsive in behavior without the 2-s precursor. The significant aspect of this exercise is that the precursor arrival is not just the foreshock but also contains the main shock. The larger second arrival is composed of the reflected phases from the free surface. Because the short-period instrument is sensitive to very short time scale effects, there is an apparent lag in travel time as the long-period instrument reacts to the major long-period nature of the displacement pulse. As shown in Figure 12, this gives rise to slow buildups to the $\boldsymbol{P}$ arrival. In fact, this is a very common characteristic of the Koyna observations.

Figure 11 also demonstrates the extreme interaction between the direct wave and surface reflections through the comparison of the delta function responses and long-period wave forms. Assuming that the phase interpretations made for the short-period records are correct, the estimated error in depth for the hypocenter is about $\pm 1.5 \mathrm{~km}$, still very small but larger than that estimated by the error ellipsoids.

This agreement between the short- and long-period depth determinations also brings up an important but subtle point. The model is a simple point dislocation with no finiteness. Since no finiteness effects are apparently resolvable, the depth agreements imply that at least teleseismically the Koyna source radiation behaved as if it were coming largely from one localized spot. The simple dislocation model seems justified on this basis.

The major inadequacy in the short-period modelling is the lack of signal duration after the initial arrivals. Reasons for this are bountiful, such as fine source crustal structure, complicated receiver structure, and more source time function effects. The preferred speculation is that earth structure, both at a source and at a receiver, is responsible. Using the Koyna Dam accelerograms, one can estimate a maximum limit for source duration, assuming that these recordings represent all the major source processes. Figure 13 shows the three components which were situated at about $10-$ to $20-\mathrm{km}$ distance from any of the epicenters obtained. By interpreting the lowamplitude first arrival as the $P$ wave, which triggered the instrument, and the larger second arrival as the $S$ wave, a maximum source duration of about $8 \mathrm{~s}$ is obtained by using the length of the $S$ wave train. This is maximum because any structural effect such as reflections and refractions will tend to lengthen the record. This $P$ and $S$ iriterpretation is based primarily on the short-period WWSSN records. If Indeed the foreshock and main shock have similar short-perlod character-

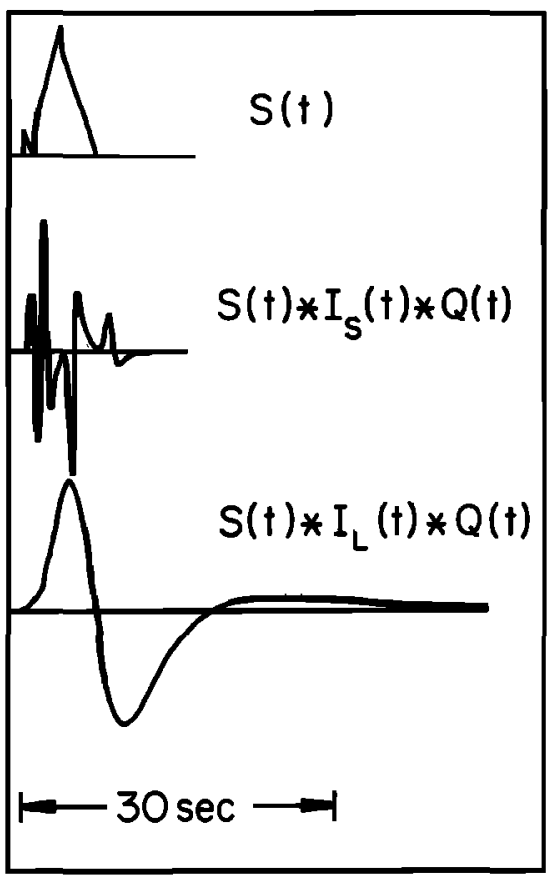

Fig. 12. Final inferred time function with the comparison of the short- and long-period instrument response.

istics, then they should not be as distinct as Gupta et al. [1971] suggest in their multiple-source interpretation of these accelerograms. These authors assume the first arrival to be entirely a foreshock and the phase here picked as $S$, the main shock. Their interpretation is also based on the teleseismic shortperiod observations; however, they picked the phases, as interpreted here, $\boldsymbol{P}$ and $\boldsymbol{P} \boldsymbol{P}$ as seen from their Figure 3 . At any rate, if all direct source effects are over within $8 \mathrm{~s}$, then all other arrivals after $8 \mathrm{~s}$ must come from scattering, either from coherent structural effects or random scattering. This maximum time duration of $8 \mathrm{~s}$ agrees very well with the estimate made from the inversion of about $6.5 \mathrm{~s}$.

There may be some basis for more high-frequency source complications in the first $8 \mathrm{~s}$ of the short-period records. A prominent third arrival, modelled here as a sharp peak on the triangular time function (Figures 11 and 12), occurs in many short-period records. However, there is not enough consistency between the records to accurately pick an arrival time in order to do a relative location study. The phases are not coherent, and often first arrivals are emergent, rendering any interpretations suggestive at best.

Recently, Singh et al. [1975] have examined the Rayleigh wave excitation from the Koyna earthquake as well as $S$ polarization angles and determined that the source mechanism is close to that of Sykes [1970] (Figure 4a). They obtained a strike of $\mathrm{N} 10^{\circ} \mathrm{E}$, dip of $78^{\circ} \mathrm{W}$, and rake of $175^{\circ}$ for a $10-\mathrm{km}$ deep source. Since the source is very shallow, polarization angles cannot strictly be used unless the effects of the source crust, e.g., $s S$, are adequately compensated for. To determine if their Rayleigh wave data are consistent with the focal mechanism obtained here, a search through the model space based on the amplitude data at $T=50 \mathrm{~s}$ (their Table 5) was made. A least squares procedure was set up to test all orientations between $60^{\circ}$ sectors in the angles with a $4^{\circ}$ increment. The radiation pattern was taken from $\mathbf{H a r k r i d e r ~ [ 1 9 7 0 ] ~ f o r ~ a ~} 10-\mathrm{km}$ source depth. This procedure yielded the result that the focal mechanism presented here was a better fit to the 50 -s period 

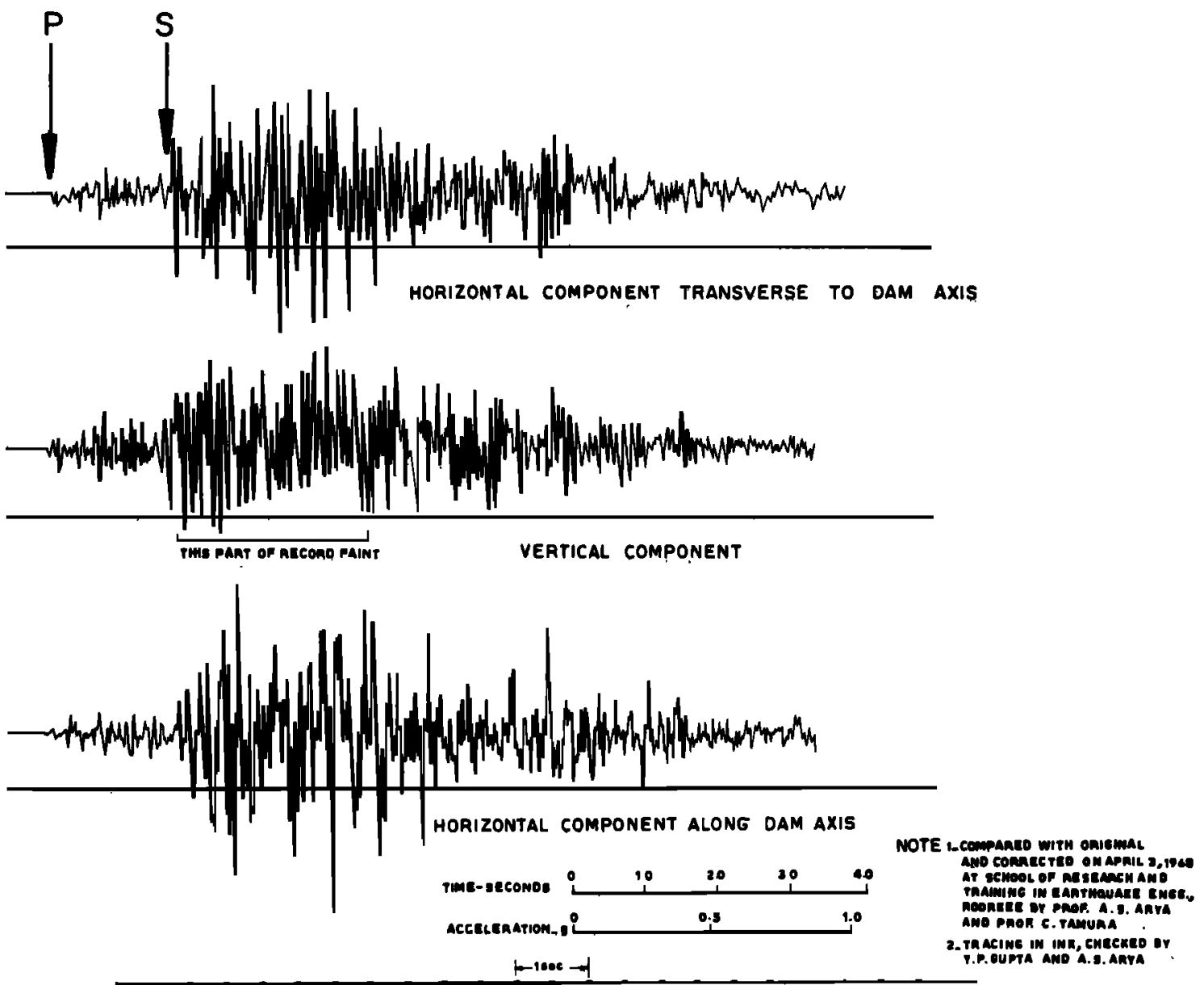

Fig. 13. Koyna accelerograms [after Krishna et al., 1969].

Rayleigh wave data than the mechanism presented by Singh et al. [1975]. However, the region of the model space examined contained two minimums which were qualitatively close to both orientations. Considering the scatter and inconsistencies in this spectral data, any solution should be considered highly ambiguous.

\section{Discussion}

The probable reasons for the major inconsistencies in the various source mechanisms obtained for the Koyna earthquake are multiple. First, the earthquake was relatively small in moment and combined with the small precursor produced emergent arrivals. Add the usual low-amplitude noise; first arrivals become obscure, if not impossible to read. Many of the direct wave polarities deduced in this study are plainly contradictory to other studies. For example, the stations which control the direction of fault dip, assuming that the strike is correct, PMG, CTA, ADE, and MUN, are dilatation here but were picked compression by Gupta et al. [1971]. The particular fault orientation and depth also helped in this process. At many stations the orientation produced large surface reflections with very small direct arrivals, making it difficult to interpret just what the first arrival represented. The strength of the method outlined here is that it minimizes these difficulties by using the wealth of relative time and amplitude information contained in the whole wave form. If the source is relatively simple, both the $P$ and the $S$ radiation fields are used to constrain the solution, incorporating those observations which have the highest quality rather than using a large quantity of less reliable first-motion data.
The question of just what fault caused the Koyna earthquake and where it is located seems to be unresolved. One school of thought [Gorbunova et al., 1970; Tsai and Aki, 1971] infers that the Koyna fault is very deep, $55-80 \mathrm{~km}$, yet extends to the surface to produce the high intensities observed. The duration, size, and crustal phase content of the body wave pulses observed clearly reject this hypothesis and are consistent with the other school that infers that the Koyna fault has a shallow source [Gupta et al., 1969, 1970; Dutta, 1969]. The orientation question has been addressed and implies that there is a major left lateral strike-slip fault with some dip-slip component near the Koyna Dam. The most logical place to put this fault would be at the area of maximum intensity and observed ground breakage. Several lines of evidence suggest this interpretation. First, the orientation of the focal mechanism agrees very favorably with the strike and left lateral en echelon character of observed fissures in the meizoseismal area. If the average $S$ - $P$ time from the Koyna accelerograms is taken with the depth determination, values of $10-14 \mathrm{~km}$ are obtained for the epicentral location assuming various plausible. crustal models. This puts the epicenter (Figure 14) slightly to the east of the trace of the fissures assuming that the IMD epicenter indicates the general direction away from the dam. This eastward shift also supports the direction of dip obtained if indeed the surface fissures are the direct manifestation of a buried fault. The intensity data [Guha et al., 1970] are also consistent with this model where the contours in Figure 14 have been drawn with respect to Guha's Figure 21. Some independent evidence for a major fault along this trend comes from anomalies in the correlation of erosion surfaces (D. T. 
Snow, personal communication, 1975), although some gravity work done near the fissures south of the Koyna River shows no significant gravity anomalies [Kailasam and Murthy, 1969].

On a more general level the inversion of this shallow earthquake has some far-reaching implications for currently used procedures. The radical structural interaction caused by the various boundaries in the crust coupled with the radiation pattern of the source absolutely precludes the use of simple whole space models for interpretations involving shallow sources unless the depth and time function is sufficient to keep these effects well separated from the actual direct arrivals. Using the whole body wave form instead of being limited by a sometimes ambiguous first-motion pick is far superior in constraining a focal mechanism, since it incorporates much more information by using both the $\boldsymbol{P}$ and the $S$ radiation patterns. Although first-motion studies are obviously still useful and easy to do, they can be supplemented by wave form interpretations when a shock has poor station coverage. An added advantage is that an independent depth determination can be made when the surface reflections are identified.

\section{Conclusions}

The use of point dislocations in a layered half space coupled to a formal generalized inverse proved to be a very useful tool in determining the focal parameters of the Koyna earthquake. The parameters obtained by using $13 P$ and $6 \mathrm{SH}$ wave forms were dip, $67^{\circ}$ to the east; strike, $\mathrm{N} 16^{\circ} \mathrm{E}$; rake, $-29^{\circ}$ plunging northeast; all angles, $\pm 6^{\circ}$; depth, $4.4 \pm 1.5 \mathrm{~km} ; \delta t_{1}, 2.5 \pm 0.5 \mathrm{~s}$, $\delta t_{2}, 3.9 \pm 1.0 \mathrm{~s}$ for a triangular time pulse; and moment, $3.2 \pm$ $1.4 \times 10^{25}$ dyn $\mathrm{cm}$.

Approximately the first $25 \mathrm{~s}$ of the long-period $\boldsymbol{P}$ and $\mathrm{SH}$ wave forms could be explained, within the uncertainties of the crustal model, by a simple point dislocation in a two-layered crust. The $\boldsymbol{P}$ wave signature is almost entirely controlled by local crustal reflections and phase conversions, although the $S H$ waves are visibly affected much less by the structure. The radical interference effects caused by the coupling of source radiation and crustal boundaries severely encroach on the applicability of interpretive methods which assume a homogeneous whole space.

The short-period $\boldsymbol{P}$ waves could only be modelled approximately but indicate that crustal structure can explain the relative times and amplitudes of the first major arrivals. Probable short-period source effects include a small precursor event which occurred approximately $1 \mathrm{~s}$ before the main shock. Possible later arrivals up to a maximum of $8 \mathrm{~s}$ after the first arrival may be other source effects, but there is ambiguity in this type of interpretation caused by uncertainty in the source crustal structure.

In interpreting arrivals on the Koyna accelerograms as $\boldsymbol{P}$ and $S$ waves an estimate of $8 \mathrm{~s}$ is made for maximum source duration. This agrees very well with the estimate of $6.5 \mathrm{~s}$ made from the body wave inversion. The shallow depth determination, isoseismal evidence, and body wave fits preclude the interpretation that the Koyna source was deep seated and demonstrate that it was indeed a very shallow earthquake. An argument can be made by using the accelerogram $S$-P time, depth, and location of isoseismals that the epicenter lay a few kilometers southeast of the fissuring and the fissures in the meizoseismal area are the surface expression of the Koyna fault.

The methods outlined here should prove useful in other focal mechanism problems involving small complications in the body waves which obscure first motions yet leave the major portion of source information preserved in the general wave shapes.

\section{APPENDIX}

The inversion formulation used in this paper is taken directly from Wiggins [1972] in notation and method and incorporates some important techniques discussed by Mellman et al. [1975].

To express the difference between the observations and calculated models, $O_{j}-C_{j}$, a transformation will be made on the data and synthetic seismograms which will minimize and eliminate some undesirable effects on the inversion. After Mellman et al. [1975], define a correlation function, $\phi$, by the following:

$$
\begin{aligned}
\phi\left(f(t), g\left(t, P_{\imath}\right)\right)=\max _{-\infty<r<\infty} \int_{-\infty}^{+\infty} f(t) g\left(t+\tau, P_{i}\right) d t \\
\cdot\left[\int_{-\infty}^{+\infty} f^{2}(t) d t \int_{-\infty}^{+\infty} g^{2}\left(t, P_{i}\right) d t\right]^{-1 / 2}
\end{aligned}
$$

where $f(t)$ is observed time series and $g\left(t, P_{t}\right)$ is synthetic seismogram. This correlation function has several nice advantages. The first is that it circumvents inverting to every time point on the seismogram, which would make the problem very nonlinear away from the optimal model. The function has the additional properties that it is totally insensitive to absolute travel time and absolute amplitude. It compares shapes only. It is very sensitive to relative amplitudes and relative times within the time series, however. So in effect it reduces the comparison of two time series into one number. The elements of the $\Delta C^{\prime}$ vector then become

$$
O_{\jmath}-C_{\jmath}=1-\phi\left(O_{\jmath}, C_{\jmath}\right)
$$

The elements of the derivative matrix, $A^{\prime}$, are now defined in terms of the correlation function, that is,

$$
\frac{\partial C_{i}}{\partial P_{i}}=\frac{\partial \phi\left(O_{i}, C_{i}\right)}{\partial P_{i}}
$$

The partial derivatives can be calculated numerically, but this requires that at least two different models have to be calculated for every derivative. In practice, model calculations are the most time consuming operation, so it is desirable to find derivatives some other way. In this paper we will pursue the

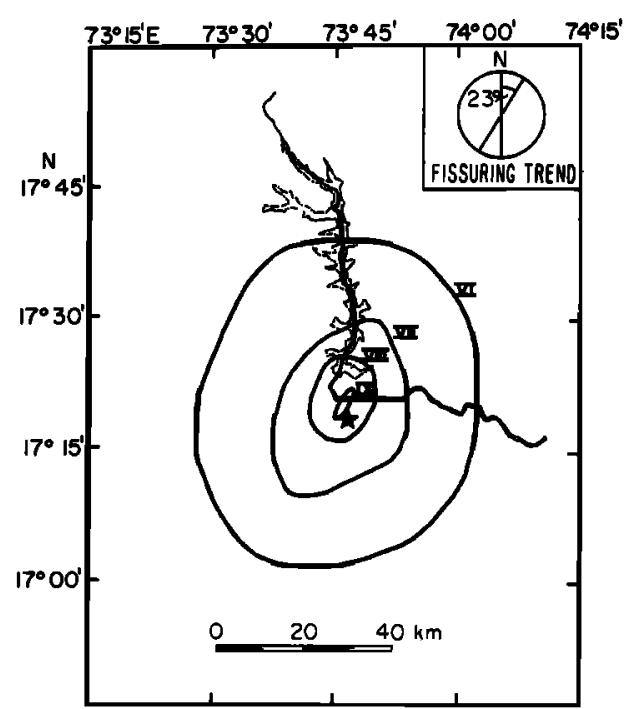

Fig. 14. Isoseismals based after Guha et al. [1970, Figure 21] showing the inferred location of the Koyna epicenter as a star. 
approach of using analytical expressions for the derivatives. Consider (A4):

$$
\phi=\phi\left(\tau, P_{l}\right)
$$

where $\tau$ is the relative time lag. Therefore, by the chain rule,

$$
\frac{\partial \phi\left(\tau, P_{i}\right)}{\partial P_{i}}=\left(\frac{\partial \phi}{\partial P_{i}}\right)_{\tau}+\left(\frac{\partial \phi}{\partial \tau}\right)_{P_{i}} \frac{\partial \tau}{\partial P_{i}}
$$

We choose to evaluate this expression near $\tau=\tau_{0}$, the relative lag at maximum correlation, so we obtain

$$
\lim _{\tau \rightarrow \tau_{0}}\left[\frac{\partial \phi}{\partial P_{i}}\left(\tau, P_{i}\right)\right]=\left(\frac{\partial \phi}{\partial P_{i}}\right)_{r_{0}}+\lim _{\tau \rightarrow r_{0}}\left[\left(\frac{\partial \phi}{\partial \tau}\right)_{P_{i}} \frac{\partial \tau}{\partial P_{i}}\right]
$$

The second term on the right vanishes, since the change in $\phi$ with respect to the lag, $\tau$, at the peak of the correlation is zero. Therefore in the sense of (A6) we have

$$
\frac{\partial \phi}{\partial P_{i}}\left(\tau_{0}, P_{\imath}\right)=\left(\frac{\partial \phi}{\partial P_{i}}\right)_{\tau_{0}}
$$

Substituting (A1) into (A7), we obtain

$$
\begin{gathered}
\left(\frac{\partial \phi}{\partial P_{i}}\right)_{r_{0}}=-\left[\int_{-\infty}^{+\infty} g^{2} d t\right]^{-1} \cdot\left[\int_{-\infty}^{+\infty} g\left(\frac{\partial g}{\partial P_{i}}\right) d t\right] \cdot \phi \\
+\left[\int_{-\infty}^{+\infty} g^{2} d t \int_{-\infty}^{+\infty} f^{2} d t\right]^{-1 / 2}\left[\int_{-\infty}^{+\infty} f\left(\frac{\partial g}{\partial P_{i}}\right) d t\right]
\end{gathered}
$$

The expressions for the derivatives of $g$ are all straightforward and can be simply found by differentiating the following general equation for a seismogram (with summation convention):

$$
g(t)=B_{j} S_{j}\left\{t-\tau_{L_{j}}\right\} *\left[\alpha_{t}, \delta\left\{t-\tau_{\left.S_{t}\right\}}\right\} * I(t) * Q(t)\right.
$$

where

$$
j \quad \text { index of } j \text { th point dislocation; }
$$

$i$ index of $i$ th ray;

$B_{j}$ relative amplitude of $j$ th source;

$S_{\mathcal{J}}\left(t-\tau_{L_{j}}\right)$ parameterized time function of $j$ th source;

$\tau_{L j}$ relative time lag of $j$ th source;

$\alpha_{i j}$ amplitude of $i$ th ray, $j$ th source;

$\tau_{a j}$ relative travel time of $i$ th ray, $j$ th source;

$\delta\left(t-\tau_{a, j}\right)$ lagged Dirac delta function.

Thus a factor of 2 in speed on the computer is obtained since (A9) requires only one model calculation. This savings is significant with large data sets. Storage requirements, however, are substantially increased because of all the derivatives of $\boldsymbol{g}$ needed, each of which is a time series.

The inversion procedure is stabilized by using the 'cutoff' method described by Wiggins [1972]. In the inversion presented here, however, this proved to be unnecessary, so that the generalized inverse reduced to a least squares inverse.

By the very nature of the problem, noise introduces peculiar nonlinearities near the minimums in the model space [Mellman and Burdick, 1975]. To counteract these effects a step size parameter is introduced to further convergence. Instead of reparameterizing by using $\Delta \boldsymbol{P}^{\prime}$, the parameter change matrix, $\gamma \cdot \Delta P^{\prime}$, is used, where $\gamma$ is the percentage step size. In practice, after each iteration, several models are calculated by using a certain percentage of the step size determined by the inversion in the direction of the vector $\Delta P$, the weighted parameter changes. A measure of error.

$$
\epsilon_{1}=\left\{\sum_{i=1}^{m} \frac{\Delta C_{i}^{2}}{\sigma_{j}^{2}}\right\}^{1 / 2}
$$

where $\sigma_{f}^{2}$ is the variance of $j$ th datum, is used to determine the goodness of fit. After four points on the $\epsilon_{1}-\gamma$ plane have been determined, up to the full step, a cubic polynomial is fit through the points by using the Lagrange interpolation formula and then analytically differentiated to find the minimum. This value is then used as the step size.

Acknowledgments. I wish to extend my gratitude to Larry Burdick and George Mellman for use of their WWSSN short-period instrument response and for the many discussions along with Don Helmberger on source modelling and inversion theory. I would also like to thank Wayne Thatcher for a critical review of the manuscript.

This research was supported by the Advanced Research Projects Agency of the Department of Defense and was monitored by the Air Force Office of Scientific Research under contracts F44620-72-C-0078 and F44620-72-C-0083. This is contribution 2661, Division of Geological and Planetary Sciences, California Institute of Technology, Pasadena, California.

\section{REFERENCES}

Abe, K., Fault parameters determined by near- and far-field data: The Wakaso Bay earthquake of March 26, 1963, Bull. Seismol. Soc. Amer., 64, 1369-1382, 1974.

Aki, K., Recent results on the mechanism of earthquakes with implications for the prediction and control program, Tectonophysics, 14, 227-243, 1972.

Alewine, R. W., Application of linear inversion theory toward the estimation of seismic source parameters, Ph.D. thesis, Calif. Inst. of Technol., Pasadena, 1974.

Ben-Menahem, A., S. W. Smith, and T. L. Teng, A procedure for source studies from spectra of long-period seismic waves, Bull. Seismol. Soc. Amer., 55, 203-255, 1965.

Bollinger, G. A., Determination of earthquake fault parameters from long-period $P$ waves, $J$. Geophys. Res., 73, 785-807, 1968.

Brune, J. N., Tectonic stress and the spectra of seismic shear waves from earthquakes, J. Geophys. Res., 75, 4997-5009, 1970.

Carpenter, E. W., Absorption of elastic waves-An operator for a constant $Q$ mechanism, At. Weapons Res. Estab. Rep. 0-4366, Her Majesty's Sta. Office, London, 1966.

Dutta, T. K., A note on the source parameter of the Koynanagar earthquake of 10th December 1967, Bull. Seismol. Soc. Amer., 59. 935-944, 1969.

Fukao, Y., Focal process of a deep focus earthquake as deduced from long period $P$ and $S$ waves, Bull. Earthquake Res. Inst., Tokyo Univ., 48, 707-727, 1970.

Fukao, Y., Source process of a large deep-focus earthquake and its tectonic implications-The western Brazil earthquake of 1963, Phys. Earth Planet. Interiors, S, 61-76, 1972.

Futterman, W. I., Dispersive body waves, J. Geophys. Res., 67. 5279-5291, 1962.

Gorbunova, I. V., N. V. Kondorskoya, and N. S. Landyreva, On the determination of the extent of an Indian shock origin by kinematic data, Geophys. J., 20, 457-471, 1970.

Guha, S. K., P. D. Goshari, M. M. Varna, S. P. Agarwal, J. G. Padale, and S. C. Marwadi, Recent Seismic Disturbances in the Shivajisagar Lake Area of the Koyna Hydroelectric Project, Maharashtra, India, Central Water and Power Research Station, Poona, India, 1970.

Guha, S. K., P. D. Gosavari, B. N. P. Agarwal, J. G. Padale, and S. C. Marwadi, Case histories of some artificial crustal disturbances, in Proceedings of Conference on International Colloquium on Seismic Effects of Reservoir Impounding. Elsevier, New Y ork, 1976.

Gupta, H., H. Narain, B. K. Rastogi, and I. Moham, A study of the Koyna earthquake of December 10, 1967, Bull. Seismol. Soc. Amer., 59, 1149-1162, 1969.

Gupta, H. K., B. K. Rastogi, and H. Narain, The Koyna earthquake of December 10, 1967: A multiple seismic event, Bull. Seismol. Soc. Amer., 61, 167-176, 197I.

Hagiwara, T., A note on the theory of the electromagnetic seismograph, Bull. Earthquake Res. Inst., Tokyo Univ., 36, 139-164, 1958.

Hanks, T. C., and M. Wyss, The use of body-wave spectra in the determination of seismic-source parameters, Bull. Seismol. Soc. Amer., 62, 561-589, 1972.

Harkrider, D. G., Surface waves in multilayered elastic media, 2, Higher mode spectra and spectral ratios from point sources in plane layered earth models, Bull. Seismol. Soc. Amer., 60, 1937-1987, 1970. 
Helmberger, D. V., Generalized ray theory for shear dislocations, Bull. Seismol. Soc. Amer., 64, 45-64, 1974.

Kailasam, L. N., P. R. Pant, S. M. Lahiri, and K. R. M. Simha, Seismic investigations in the Deccan trap areas of Maharashtra and parts of Mysore and Andhes Predesh, Mem. Geol. Surv. India, 100, 113-116, 1969.

Kailasam, L. N., and B. G. K. Murthy, Geophysical investigations in the earthquake affected areas of Koyna, Satora district, Maharashtra, Mem. Geol. Surv. India, 100, 177-122, 1969.

Khattri, K. N., The Koyna earthquake-seismic studies, in Fourth Symposium on Earthquake Engineering. pp. 369-374, Roorkee, India, 1970.

Krishna, J., A. R. Chondrasekaran, and S. S. Saini, Analysis of Koyna accelerogram of December 11, 1967, Bull. Seismol. Soc. Amer., 59 1719-1731, 1969.

Langston, C. A., and D. V. Helmberger, A procedure for modelling shallow dislocation sources, Geophys. J., 42, 117-130, 1975.

Lee, W. H., and C. B. Raleigh, Fault-plane solution of the Koyna (India) earthquake, Nature, 233, 172-173, 1969.

Long, R. E., K. Sundaraligam, and P. K. H. Maguire, Crustal structure of the East African rift zone, Tectonophysics, 20, 269-281, 1973

Mellman, G., L. Burdick, and D. Helmberger, Determination of source parameters from body wave seismograms (abstract), Earthquake Notes, 46, 44, 1975.

Minster, J. B., T. H. Jordan, P. Molnar, and E. Haines, Numerical modelling of instantaneous plate tectonics, Geophys. J., 36, 541-576, 1974.

Mitchell, B. J., and M. Landisman, Electromagnetic seismograph constants by least-squares inversion, Bull. Seismol. Soc. Amer., 59. 1335-1348, 1969.

Narain, H., Crustal structure of the Indian subcontinent, Tectonophysics, 20, 249-260, 1973.

Narain, H., and H. Gupta, Koyna earthquake, Nature, 217, $1138-1139,1968$.
Niazi, M., Source dynamics of the Dasht-e Bayaz earthquake of August 31, 1968, Bull. Seismol. Soc. Amer., 59, 1843-1861, 1969.

Oike, K., On the nature of the occurrence of intermediate and deep earthquakes, 2, Bull. Disaster Prev. Res. Inst., Kyoto Univ., 21 . 153-178, 1971 .

Singh, D. D., B. K. Rastogi, and H. K. Gupta, Surface-wave radiation pattern and source parameters of Koyna earthquake of December 10, 1967, Bull. Seismol. Soc. Amer., 65, 711-731, 1975.

Stauder, W., The focal mechanism of earthquakes, in Advances in Geophysics, 9th ed., edited by H. E. Landsberg and J. Von Mieghem, Academic, New York, 1962.

Sykes, L. R., Seismicity of the Indian Ocean and a possible nascent island arc between Ceylon and Australia, J. Geophys. Res., 75, 5041-5055, 1970.

Tandon, A. N., and H. M. Chaudhury, Koyna earthquake of December, 1967, Sci. Rep. 59, India Meteorolog. Dep., 1968.

Teng, T., and A. Ben-Menahem, Mechanisms of deep earthquakes from spectrums of isolated body-wave signals, J. Geophys. Res., 70, 5157-5170, 1965.

Tsai, Y-B., and K. Aki, The Koyna, India, earthquake of December 10, 1967 (abstract), Eos Trans. AGU, 52, 277, 1971.

Wiggins, R. A., The general linear inverse problem: Implications of surface waves and free oscillations for earth structure, Rev. Geophys. Space Phys., 10, 251-285, 1972.

Wu, F. T., Parkfield earthquake of June 28, 1966: Magnitude and source mechanism, Bull. Seismol. Soc. Amer., 58, 689-709, 1968.

Wyss, M., and J. N. Brune, The Alaska earthquake of 28 March 1964: A complex multiple rupture, Bull. Seismol. Soc. Amer., 57, 1017-1023, 1967.

(Received October 6, 1975; revised February 5, 1976; accepted February 9 , 1976.) 